Apresentação | Introduction

\title{
Arte e cidade: policromia e polifonia das intervenções urbanas
}

\section{Art and city: polychromy and polyphony of urban interventions}

Cornelia Eckert ${ }^{\star}$

* Universidade Federal do Rio Grande do Sul - Porto Alegre, RS, Brasil chicaeckert@gmail.com

https://orcid.org/0000-0002-2815-7064

Glória Diógenes **

** Universidade Federal do Ceará - Fortaleza, CE, Brasil gloriadiogenes@gmail.com

https://orcid.org/0000-0002-7494-8553

Ligia Dabul ${ }^{\star \star *}$

*** Universidade Federal Fluminense - Niterói, RJ, Brasil ligia.dabul@gmail.com

https://orcid.org/0000-0002-6224-9720

Ricardo Campos ${ }^{\star \star * *}$

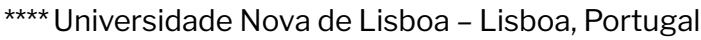

Pesquisador associado ao CICSNova

rmocampos@yahoo.com.br

https://orcid.org/0000-0003-4689-0144 
Marcel Mauss, um dos precursores da antropologia moderna, escreveu em 1947 um Manual de etnografia (Mauss, 1972). Estrategicamente orienta para uma pesquisa inovadora, a do trabalho de campo sistemático, meticuloso e ético, atento a um novo terreno conceitual, o do fato social total, que inaugura a antropologia simbólica. Ensina uma metodologia com firme formação na antropologia, mas ligada às paisagens interdisciplinares. Não negligencia nenhuma das técnicas importantes para uma perspectiva processual de análise científica, mas coloca em destaque o método intensivo e cuidadoso para o estudo de uma sociedade. Aos pesquisadores, novatos ou experientes, recomenda a perspectiva comparativa, a atenção aos diferentes fenômenos da vida social. Não somente dar atenção às questões econômicas e administrativas, mas ao conjunto das qualidades criativas em que repousa o mundo das práticas simbólicas. Assim, todas as artes e ofícios de produção, sem exceção, são simetricamente importantes. Todas as sociedades em suas ciências, estéticas, suas representações coletivas, seus fenômenos morais e jurídicos, suas expressões corporais, suas expressões religiosas e de sociabilidades. ${ }^{1}$

Misturam-se as almas e as coisas, como os fenômenos estéticos, técnicos e éticos que revelam noções de rítmica, de socialidade, de individualidade e de coletividade, de vida. Boas (1927), na sua obra Primitive art, também valoriza o tema da arte como ritmo, o ritmo da vida criativa, sensível. Arte é vida em sua sensorialidade, suas linguagens, suas emoções, seus prazeres, cores, sons, múltiplas sensações e sempre misturas de faculdades criadoras, dos mistérios da intuição e da criação. De tal modo, a cartografia das artes apresenta-se como uma necessidade absoluta, concebem os mestres. Mauss advoga, em suma, que é preciso procurar ao mesmo tempo o que singulariza uma época ou uma sociedade, elemento comum na obra de Boas.

Não precisamos mais justificar a importância de um número da revista dedicado ao tema "Arte e cidade", citando autores clássicos ou contemporâneos. Desde a primeira impressão na parede, na pedra, na terra, no barro, na areia, a arte vibra na memória coletiva, desvenda o passado e constrói o futuro, resguarda o afeto e descreve o conflito, evoca as crenças, as ideologias e reúne

1 A atividade de co-organização deste número do pesquisador Ricardo Campos ocorre no âmbito de dois projetos financiados pela Fundação para a Ciência e Tecnologia (IF/01592/2015 e PTDC/ SOC-SOC/28655/2017). 
as energias para a constante imaginação. Tal fulgor deve-se à necessidade premente de comunicarmos com o outro, de estabelecermos teias de significado que passam por linguagens distintas. E comunicamos através de instrumentos e canais plurais. À falta de uma folha de papel, escrevemos na parede. Escrever (ou desenhar) na parede tem outra repercussão coletiva, chega a uma plateia mais vasta. E, como tal, desde tempos imemoriais que desenhamos, escrevemos ou pintamos muros e paredes, com o intuito de materializar (e partilhar) pensamentos, imagens e imaginários.

Aquilo que comunicamos na cidade, através das suas superfícies, é entendido de forma diferente pelos seus múltiplos habitantes. Nem tudo se encaixa na categoria de arte, tal como socialmente é definida. O que nos conduz, também, a uma reflexão sobre o papel destas formas de comunicação não artísticas e, em muitos casos, consideradas disruptoras e desobedientes, incitando ao seu silenciamento. São conhecidos os casos de zelo extremo por parte das autoridades públicas, preocupadas em conter certas "pragas urbanas" manifestadas por essas vozes desobedientes, atentatórias da moral e dos bons costumes no uso da cidade. Graffiti ou pixo ${ }^{2}$ são, muitas vezes, alvos de perseguição e apagamento, no âmbito de processos de higienização urbana.

É singular dizer que as cidades contemporâneas estão mais coloridas de graffiti, de estêncis, de lambes ou colagens, além de outras formas de arte urbana e arte de rua. Diferentes indivíduos e grupos participam dessa construção da paisagem visual da cidade, pintando muros e paredes, colorindo edifícios, colando stickers, fazendo gardening guerrilla, expondo-se eles mesmos aos olhares, etc. E são, muitas vezes, essas expressões minoritárias, vernaculares, transgressoras, que afrontam o conceito de arte oficial e os modelos de uma cidade planificada e asséptica.

Daí que a paisagem visual da cidade hoje seja composta por uma multitude de expressões pictóricas e estéticas que convivem com a arte pública oficial. As variadas intervenções das artes de rua - mesmo que isso ocorra por meio de um tipo de leitura sem palavras, como no caso das tags - produzem narrativas da cidade tal qual seu conjunto arquitetônico e seus monumentos históricos. Essas artes frequentemente escapam do que é consentido, contrariando os

2 Mantemos aqui a grafia com X, de acordo com o uso "nativo", em vez do CH do registro oficial. 
"juízos de gosto" das belas artes, sendo categorizadas, por vezes, como expressões de vandalismo e ações de poluição da paisagem. As artes de rua provocam não apenas um outro regime estético, tal qual se refere Jacques Rancière (2009), como agem promovendo novos usos e práticas de espaço (Certeau, 1994), diversificando fabulações e compondo novas trilhas narrativas da/na cidade.

Todo esse palimpsesto de imagens e de linguagens que emerge por meio das artes de rua, embora se multiplique, de forma curiosa, concomitantemente, remete ao que ali escapa, ao que parece invisível. A efemeridade dessas artes, tendo em vista suas constantes ameaças de apagamento, de branqueamento de paredes e muros, acaba assumindo contornos de uma materialidade em movimento, como se estabelecessem um tipo de acontecimento em forma ininterrupta de aparição e desaparição (Peixoto, 2004, p. 51). "Sendo o visual uma qualidade espacial do visível que só se produz em imagens muito raras" (Peixoto, 2004, p. 41), as artes urbanas atuam nesse entre, figuração de um concreto que se mostra e que desaparece da paisagem. Embora se proliferem nas cidades de todo o planeta e assumam formas pluriestéticas, as artes de rua tanto adquirem uma destacada visibilidade como, ao mesmo tempo, encarnam a qualidade da invisibilidade e da indiscernibilidade. Trata-se, assim, de rastrear outros mapas e rotas dos significados do que seja arte, cidade, e dos elementos que compõem suas imagens e narrativas.

Valorizamos os artistas como autores, que se expressam e manifestam, agem por seus corpos que observam e reagem, e que, por vezes, como aqui, pesquisam, compõem a arte que está nas ruas da cidade. Atrelando as visualidades aos seus tempos, aos seus deslocamentos e movimentações, esses corpos que interagem com as coisas que fazem e percebem nas ruas também conduzem o fluxo dessa arte e potencializam, colocando-os ainda mais em aberto, os ritmos e a própria matéria das cidades. Dessa maneira, por diversos mecanismos, as imagens e as linguagens das artes feitas nas ruas se constituem, estendem e vibram fundadas em variadas experiências dos atores sociais implicados em todas as suas vias de criação e significadas e disseminadas em percursos, boa parte das vezes estabelecidos deliberadamente e que nem sempre se revelam ao olhar.

Desse modo, ao tratar do tema da cidade no contexto contemporâneo pode ser de grande valia avizinhar-se da presença desse mundo sensível, e de suas expressões estéticas no espaço público. A arte, ou a "arte pública", se espraia de muitas maneiras e por diferentes espaços urbanos, bairros, ruas, muros, 
paredes, calçadas, postes. Diferentes tons colorem as cidades, frases falam da vida, os rastros se acumulam diante do olhar do passageiro, no curso da observação do errante. Arte geralmente legitimada e patrocinada pelos poderes (públicos ou privados) seja da arte urbana, ou street art ou arte graffiti, mas também mediada por gestos ilegais, rompendo os limites do permitido, e apontando em geral para uma crítica aos jogos morais que cerceiam o direito à cidade. Diferentemente da compreensão efetuada apenas por meio de dispositivos discursivos, os antropólogos e antropólogas se veem, cada vez mais, convocados(as) a observar o urbano e a narrar a vida nesse contexto para além de suas edificações, equipamentos e patrimônios.

As expressões estéticas no espaço público sempre fizeram parte de uma certa ideia de cidade. A chamada "arte pública" representa uma certa visão daquilo que são os modelos normativos e estéticos dominantes. São expressões que celebram os valores mais consensuais e dominantes de uma determinada sociedade. No entanto, a arte na cidade não é produzida apenas por aqueles que detêm o poder de uso e planejamento do território. A cidade é vivida pelos cidadãos, que nela inscrevem as suas singularidades. A apropriação da cidade sobrevém, também, pela sua construção simbólica e estética. Tornar a paisagem citadina um território de significado, proximidade, identidade e fruição passa pela sua (de)marcação simbólica.

Neste número de Horizontes Antropológicos, reunimos artigos com base em pesquisas sociais e etnográficas que mobilizam na cidade as cores, sons e tons que reúnem artistas em suas práticas, que interpretam as intervenções artísticas urbanas. São textos que atualizam as expressões criativas nas cidades pesquisadas, que informam as políticas públicas ou suas ausências, que esclarecem os processos de politização das expressões ou reconhecem em suas marcas as denúncias, ou os silêncios de participações e as invisibilidades das intolerâncias e discriminações. A vida é ritmo, a cidade é ritmo, a arte é ritmo. A nós, como pesquisadores participantes da Rede de Pesquisa Luso-Brasileira em Artes e Intervenções Urbanas e do projeto luso-afro-brasileiro Todas as Artes, Todos os Nomes, cabe a alegria de compartilhar artigos inéditos que respondem a esta pergunta, que buscam respostas em todos os sentidos sobre a arte na cidade, sobre a cidade e a arte.

Abrimos nosso número com o artigo intitulado "Nothing is forever: um ensaio sobre as artes urbanas de Miguel Januário \pm MaisMenos \pm ", de autoria de 
Paula Guerra. Paula analisa o impacto das intervenções artísticas politicamente engajadas do artista Miguel Januário, na última década em Portugal, tendo como pano de fundo uma severa crise econômica, financeira e social atravessada por esse país. A autora parte do pressuposto que as manifestações artísticas de Miguel Januário tencionam não apenas denunciar os reveses da referida crise, mas também intervir/agir, promovendo ondas de incitamento, atos insurgentes e um processo significativo de autorreflexidade dos atores nela envolvidos. Uma das propostas instigantes do texto, para além de uma abordagem meramente descritiva, é a de demarcar os planos de inter-relação entre a arte e as ciências sociais, nomeadamente a sociologia. Ao longo do artigo, a autora ressalta a emergência de uma nova arte urbana que está na base de novas artes públicas, que falam e apreendem a cidade como "território poliédrico de comunicação visual". Tomando como base a discussão sobre artivismo que medra novos movimentos sociais de natureza anticapitalista, o artigo coloca em cena pautas de revisão e reconsideração da dimensão política e responsabilidade social dos artistas. Miguel Januário, nascido no Porto, torna-se emblemático personagem, inicialmente na produção de antimarcas publicitárias, na condição de designer gráfico, como forma de criticar "o sistema usando suas próprias armas". Segundo a autora, Miguel Januário se reapropria de símbolos do país e, numa "espécie de estilo saramaguiano de subverter expressões conhecidas e provérbios", produz frases e performances de impactante matéria crítica e força subversiva no que tange à situação portuguesa diante da crise. Como ressalta a autora, a performance intitulada Ego sum panis vivus faz despertar um revelador artivista. Finalmente, a autora destaca que a proposta de renovação epistemológica a que se propõe o artigo permite que os leitores possam identificar uma análise mais fina da relação entre arte e crise e, também, entre arte e sociedade.

Por seu turno, Andrea Pavoni, em seu artigo intitulado "Speculating on (the) urban (of) art: (un)siting street art in the age of neoliberal urbanisation", aborda de forma teoricamente densa um conjunto de impasses e paradoxos que rodeiam a arte urbana contemporânea. Aquilo que o artigo retrata é o papel que a arte urbana tem desempenhado, atualmente, a serviço de uma agenda levada a cabo pelos poderes públicos, nomeadamente instrumentalizando essas expressões em benefício da revitalização e promoção do espaço público. Vários autores têm vindo, precisamente, a referir que a gradual legitimação e 
institucionalização do graffiti e da arte urbana permitiram que estes se convertessem numa mais-valia urbana para a cidade. A sua relevância não deve ser desligada da retórica da cidade criativa, que tem sido largamente promovida nas últimas décadas no contexto das cidades neoliberais. Nesse âmbito, o autor faz uso de alguns exemplos como ponto de partida para esta reflexão: 0 do bairro de Kreutzberg em Berlim ou o do projeto Porto Maravilha no Rio de Janeiro, iniciado em 2009 e que se definiu como um dos maiores projetos de revitalização do Brasil, tendo por objetivo a recuperação econômica, turística e habitacional de uma área urbana longamente esquecida. Porém, o autor vai mais longe, debatendo as diferentes perspectivas acerca da arte presente no espaço público urbano.

Na sequência, no artigo intitulado “'Graffiti é existência": reflexões sobre uma forma de citadinidade", Gabriela Pereira de Oliveira Leal baseia-se numa etnografia de natureza multissituada, realizada na cidade de São Paulo entre os anos de 2016 e 2017. No artigo, a autora propõe um deslocamento do olhar a respeito do gesto de produzir graffiti, destacando as dinâmicas de natureza social, simbólica ou afetiva que vão além da simples pintura nos muros da cidade. O seu relato vivo e denso mostra até que ponto o graffiti é uma forma de vida que se inicia na juventude e que, em muitos casos, se prolonga para a idade adulta. A biografia dos sujeitos é, a este respeito, fundamental para se perceber as mutações do campo e a forma como estes vão incorporando novas formas de conceber os seus atos estéticos na cidade. Ao longo de seu período de pesquisa, a autora acompanhou diferentes sujeitos que começaram a fazer graffiti em São Paulo entre os anos 1980 e o início dos anos 2000 - pertencentes à chamada old school e à new school. A autora relata as peculiaridades dessa cultura eminentemente urbana, de natureza global, e que abarca um conjunto diversificado de fórmulas e estilos. Falamos de tags, throw ups ou bombs. Falamos de diferentes tipos de lettering, de personagens, de murais mais ou menos complexos. Falamos, ainda, de registos ilícitos e outros lícitos. Todavia, o argumento principal da autora remete para a importância de perceber uma forma de citadinidade particular, produzida e informada pelas experiências de pintar na rua. Aqueles que fazem graffiti estabelecem uma relação complexa e criativa com o território e com o edificado urbano. Há uma série de cartografias de cidades vividas, como revela a autora, bem como uma exploração da cidade que vai bem além do espaço mais circunscrito dos bairros que os sujeitos habitam. 
O artigo de Ricardo Campos e Ágata Sequeira conduz-nos à cidade de Lisboa, relatando-nos um fenômeno relativamente recente: a turistificação da arte urbana. O título do artigo "Entre VHILS e os Jerónimos: arte urbana de Lisboa enquanto objeto turístico" é, aliás, bem explícito relativamente àquilo que está em causa nesse contexto. Lisboa, uma cidade antiga com um patrimônio histórico e monumental reconhecido mundialmente, é hoje procurada, também, por causa da qualidade da arte urbana que nos últimos anos alterou sua paisagem. Como demonstram os autores, a turistificação da arte urbana deriva de uma gradual valorização social e legitimação institucional desse tipo de expressões estéticas presentes no espaço público urbano. Esse fato tem sido reconhecido pelos poderes públicos que, em muitos contextos, têm utilizado a arte urbana como estratégia de promoção da imagem das cidades. Os autores debruçam-se sobre essa matéria a partir de uma análise que tem em consideração um conjunto de atores sociais que contribuem para a construção da arte urbana enquanto objeto turístico.

O artigo de Glória Diógenes também nos leva à cidade de Lisboa. "Conexões entre artes de rua, criatividade e profissões: circuitos e criações de Tamara Alves" parte de uma etnografia realizada em Lisboa sobre arte urbana e graffiti. O contexto da investigação se voltou para aqueles e aquelas que, mesmo sob o manto das intervenções ilegais nas ruas, desenvolviam obras comumente identificadas na qualidade de muralismo, demandando um maior tempo de execução e destreza. As artes de Tamara, personagem emblemática dessa pesquisa etnográfica, sinalizam um tipo de inserção borrada nas ruas, gerando modos peculiares de produção de bens artísticos e um singular processo de profissionalização. $\mathrm{O}$ artigo destaca a importância da pluralidade de experiências combinadas na trajetória da artista, que vão acontecendo de forma quase sempre misturada, seja por meio de um curso de belas artes, das suas intervenções nas ruas e das atividades que desenvolve como tatuadora, DJ, designer gráfica, dentre outras. Suas intervenções, identificadas como subversivas pela autora, promovem o inesperado, o acidental, como domínio e potência da arte. Há um fio, segundo a autora, que embaralha e unifica o fazer arte de Tamara no predomínio das noções de brincadeira e experimentação. Ela pinta o permitido e diz assim ganhar tintas para o ilegal. Observa-se na leitura do artigo que Tamara conecta diversificados diagramas de ação e criatividade, em que mais vale o processo que a obra final. Segundo a autora, as vias múltiplas de Tamara evidenciam que as 
experimentações por ela efetuadas constituem um dentro e um fora da arte, um dentro e um fora da lógica do trabalho e do mercado, instalando um pontilhismo entre práticas underground e ações inseridas no mainstream. A autora, por fim, aponta que, nos fazeres de Tamara Alves, o risco, os desvios, o escorrer das tintas, os gestos acidentais provavelmente contribuem para novas modulações de processos de formação profissional e aproximações entre arte, trabalho e vida.

No artigo de Marielen Baldissera, "Barraqueiras e heroínas: escritos feministas nas ruas de Porto Alegre", a poesia inscrita por mulheres no Centro Histórico e na Cidade Baixa, em Porto Alegre, por meio de variados modos - graffiti, pixos, estêncis, lambes, adesivos, grafias e figurações - é trazida para análise junto com imagens fotográficas e falas que descrevem as trajetórias sociais, intenções e as circunstâncias que cercam a prática dessa arte feminista. Concebendo as artistas como flâneuses que se deslocam, muitas vezes com riscos, apropriando-se de espaços públicos também com a imposição de seus corpos, a autora, fotógrafa e por isso ela mesma flâneuse, torna inquietos e tensiona a aparente naturalidade desses efêmeros escritos que convivem com outras tantas intervenções urbanas, apresentando questões sobre sua condição feminista, sua disseminação, sua variabilidade e a contundência com que são propostos. Perpassada pelos atributos e pertencimentos das artistas que a praticam, a arte especialmente politizada dos escritos feministas de rua tem a principal matéria de sua criação atada aos significados que causas coletivas assumem e ao modo como afetam e mobilizam essas mulheres.

Lemos em seguida o artigo "Entre calçadas, pixações e parentesco: a cidade como campo de batalha em torno das lesbo/homoparentalidades e do acesso à PMA na França", de Anna Carolina Horstmann Amorim. Um útero grávido pintado no chão, na calçada em uma avenida em Paris. Palavras pixadas nos entornos enfatizam a presença de movimento lésbico, homossexual, etc. Diferentes intervenções urbanas em diferentes tempos afetam a pesquisadora em seu tema de pesquisa: parentesco, suas famílias e trajetórias reprodutivas e de ação na construção de suas maternidades lésbicas no contexto francês. Assim, arte, cidade e relações reprodutivas, mulheres lésbicas, sexo, intervenções artísticas no meio urbano se misturam, como se misturam as almas e coisas, como já protagonizava Marcel Mauss em sua obra sobre a dádiva e o dom. Novas tecnologias no mundo ocidental contemporâneo e novas famílias homoparentais também se misturam e vibram no mundo citadino. Razões afetivas de viver que contrastam 
com as razões morais conservadoras no contexto social francês. Ambas e múltiplas razões que deixam seus rastros em pixos, em imagens, em palavras nas ruas de Paris. A autora etnografa essas manifestações e suas autorias coletivas para reconhecer os atores, suas lógicas, atualizando o debate em torno do tema da parentalidade e conjugalidade homossexual. Rastreia as intervenções artísticas e as descreve como que embalada por uma espécie de guerra de sentidos entre movimentos pró-liberdade de opções sexuais e de parentalidade e expressões de intolerância, prezando pelo moralismo colonial de mentes e espíritos. Essas disputas marcam as ações de ocupar os espaços urbanos, mote para a autora refletir sobre as formas complexas em que o biopoder atravessa as vidas pessoais, provoca movimentos sociais, estabelece interações e explicita conflitos e diferenças culturais, de classe, de valores e projetos. As pixações, as intervenções urbanas, a arte urbana, atualizam os citadinos, em seu cotidiano, as forças hegemônicas e contra hegemônicas em um tema corriqueiro: sexo, parentalidade, família, vida.

$\mathrm{O}$ artigo "Nem anônimas nem invisíveis: cidade e mulheres escritoras de graffiti", de Natalia Pérez Torres, destaca a voz e a presença das mulheres na produção urbana do graffiti. Inspirando-se de início nas Cidades invisíveis de Italo Calvino, a autora destaca a ideia de que a abordagem das cidades no âmbito da antropologia é constituída das relações e trocas que se estabelecem entre aquilo que desafia sua constituição física e o não evidente, que emerge no dorso das paisagens invisíveis. O fenômeno do graffiti, segundo a autora, assume um campo de visibilidade não destinado a ele, o muro. São expressões deslocadas, que desregulam lógicas de normalização e disciplinamento das cidades. O graffiti, de acordo com as palavras da autora, em diálogo com Roland Barthes, se inscreve nas cidades sem qualquer intenção literária ou de legibilidade, "o despreocupado num sentido de desapego institucional, de qualquer tipo de significado diáfano e reconhecível". Nessa perspectiva, como sublinha a autora, torna-se ainda mais significativa a forma de escrita das mulheres, por via de tags, no âmbito de uma prática ainda dominada por homens. Uma forma de escrita que emerge partir de seus corpos e de suas experiências. Desse modo, ela destaca que a potência da visibilidade das meninas na paisagem do graffiti, a partir da tag, de inscrição não legivel, indica um reposicionamento estratégico sobre o imaginário urbano selado com um nome e gestos de mulher.

Noutra direção, temos em "Lâmpadas, corpos e cidades: reflexões acadêmico-ativistas sobre arte, dissidência e a ocupação do espaço público", de Vitor Grunvald, 
contundente reflexão sobre inadequações e vieses políticos das próprias noções de espaço público e arte para lidar com práticas artivistas de ocupação voltadas para a afirmação radical do corpo livre. O artigo parte da análise da atuação do coletivo A Revolta da Lâmpada, formado por pessoas LGBTQIA+, surgido em dissidência da Parada do Orgulho LGBT do Rio de Janeiro de 2014 e referido a episódio de violência homofóbica ocorrido em 2010 contra Luís Alberto Betônio, agredido com duas lâmpadas fluorescentes na Avenida Paulista, em São Paulo, onde o coletivo fez sua primeira manifestação pública. Com escrita e dados etnográficos cravados na militância, o autor conduz os leitores a postos de observação potentes para a sondagem de formulações sobre a criatividade - muito próxima à experiência artística - que perpassam manifestações políticas em espaços públicos e sobre a arte, já descentrada, feita nas ruas com intenções políticas e pautas urgentes.

Finalizamos com o artigo, "Da impossibilidade de conter: intervenções urbanas e produção de subjetividade em Porto Alegre", de Guilherme Augusto Flach e Simone Mainieri Paulon. Os containers, ao surgirem em uma cidade-capital como Porto Alegre, respondem a políticas de saneamento. Ideias de higienização e segregação sustentam esse projeto moral. São estruturas metálicas espalhadas por bairros na cidade, que parecem ser corpos que destoam do cenário. Mas logo o habitante mediano se acostuma com sua funcionalidade, a não ser que seja apropriado para o inesperado: um mendigo que se abriga do frio ou um corpo inerte rompendo com a rotina almejada, uma manifestação de rua em que manifestantes explodem um container. Um pesquisador errante absorve da cidade suas lógicas, suas marcas, suas subversividades. Mais ainda, inspirado em Guattari, o errante interpreta os componentes maquínicos, produtores de subjetividades. Nessa forma ensaística, os autores enfatizam gestos, atos, vozes que materializam tensionamentos resistentes às lógicas hegemônicas da urbe. A arte urbana emerge em todo seu potencial: contesta, critica ou simplesmente colore. A presença da arte urbana aporta novas dinâmicas e complexidades e se soma às múltiplas intervenções urbanas que ritmam a cidade. Autores que tratam da intervenção urbana se sucedem citados no ensaio, bem como os próprios interventores que ressoam na memória coletiva. A cidade segue sede de múltiplas narrativas artísticas que politizam a urbe. $\mathrm{Ou}$ apenas colorem, como os containers pintados por artistas a partir da demanda do poder municipal. 
A seção Espaço Aberto traz uma entrevista com a antropóloga e cineasta Catarina Alves Costa, professora na Faculdade de Ciências Sociais e Humanas na Universidade Nova de Lisboa. Autora de uma produção fílmica com base em pesquisas antropológicas, Catarina tem seu trabalho apreciado pela rede de pesquisadores da antropologia visual no Brasil, sendo constantemente referida nos programas de aulas e oficinas de antropologia visual nos laboratórios e centros de pesquisa.

Espaço Aberto também traz o obituário, redigido por Rod Watson e Édison Luis Gastaldo, de Eric Dunning, pioneiro da sociologia dos esportes, que junto com Norbert Elias publicou o livro A busca da excitação: desporto e lazer no processo civilizacional.

Para ilustrar a capa desta edição, escolhemos o retrato do Cacique Raoni, da tribo Caiapó. O mural do brasileiro Eduardo Kobra ocupa a empena de um prédio de cinco andares na Rua António Gedeão, na zona de Marvila da cidade de Lisboa, Portugal. Fotografado por José Luís Abalos Júnior (PPGAS/UFRGS), representa um alerta para o problema das populações indígenas no Brasil e no mundo inteiro. Nascido no Jardim Martinica, bairro pobre da zona sul de São Paulo, Kobra tornou-se um dos mais reconhecidos muralistas da atualidade, com obras em cinco continentes. O grafiteiro começou a desenhar em muros clandestinamente durante sua adolescência. Autodidata, desenvolveu sua arte inspirado em artistas como o britânico Bansky, os norte-americanos Eric Grohe e Keith Haring e o mexicano Diego Rivera (Kobra, 2019).

\section{Referências}

BOAS, F. Primitive art. Oslo: Asche-houg, 1927. (Instituttet for sammenlignende Kulturforskning. Ser. B: Skrifter, 8).

CERTEAU, M. de. A invenção do cotidiano: 1: artes de fazer. Petrópolis: Vozes, 1994.

KOBRA. Biografia, 2019. Disponível em: http://www.eduardokobra.com/biografia/. Acesso em: 24 jun. 2019.

MAUSS, M. Manual de etnografia. Lisboa: Editorial Pórtico, 1972.

PEIXOTO, N. B. Paisagens urbanas. São Paulo: Senac, 2004.

RANCIÈRE, J. O inconsciente estético. São Paulo: Editora 34, 2009. 